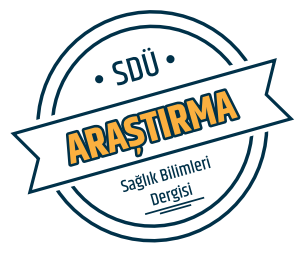

Sdü Sağlık Bilimleri Enstitüsü Dergisi / Cilt 8 Sayı 2 / 2017

\title{
Yeni Kurulan Organ Nakli Merkezimizde Yapılan Karaciğer Nakli Sonuçlarımız \\ Liver Transplantation Results in our Center Newly Established
}

\author{
İhsan Yıldız ${ }^{1}$, Mehmet Zafer Sabuncuoğlu' ${ }^{1}$, Yavuz Savaş Koca ${ }^{1}$, Filiz Solmaz Alkaya ${ }^{2}$, Altuğ Şenol ${ }^{3}$ \\ ${ }^{1}$ Süleyman Demirel Üniversitesi, Tıp Fakültesi, Genel Cerrahi AD, Isparta, Türkiye. \\ ${ }^{2}$ Süleyman Demirel Üniversitesi, Tıp Fakültesi, Anestezi ve Reanimasyon AD, Isparta, Türkiye. \\ ${ }^{3}$ Süleyman Demirel Üniversitesi, Tıp Fakültesi, Gastroenteroloji AD, Isparta, Türkiye.
}

\section{Özet}

Amaç: Karaciğer nakli, son dönem karaciğer yetersizliğinde güncel tedavi olmaya devem etmektedir. $\mathrm{Bu}$ yazıda yeni kurulan Organ Nakli Merkezimizde 30.07.2015 ile 30.07.2016 tarihleri arasında yapılan 7 kadavra donörlü karaciğer nakli sonuçlarını ve deneyimlerimizi sunmayı amaçladık.

Materyal-Method: Organlar Isparta ve bölgedeki koordinasyon sistemine bağlı hastanelerde ortaya çıkan beyin ölümü deklare edilmiş kadavralardan sağlandı. Organ eşleşmeleri sağlık bakanlığı verileri doğrultusunda gerçekleşti. Ortotopik olarak nakledilen karaciğerlerin vena kava anastomozları parsiyel klempaj uygulanarak piggyback yöntemiyle ile yapıldı. Portal ven ve hepatik arter anastomozları ise standart olarak uç-uca yapıldı. Safra anastomozları stent üzerinden uç-uca yapıldı.

Bulgular: Organ nakli merkezinin kurulduğu tarihten bu yana 9 adet kadavra donör ulusal sisteme kazandırılmış olup, 7 karaciğer nakli ise merkezimizde yapıldı. Yaş ortalaması 55,3 (45-72) olan 5 erkek, 2 kadın toplam 7 olguya kadavra donörlü karaciğer nakli yapıldı. Olguların özellikleri, ameliyat süreleri, yapılan transfüzyon, komplikasyonlar ve MELD skorları özetlenmiştir. Bir mortalite dışında hastalarımızın tümü sorunsuz olarak taburcu edildi. Bir kadın olguda 7. ayda biliyer darlık gelişti ve endoskopik olarak tedavi edildi. Bir hastamızda 6. ayda akut miyeloid lösemi tespit edilmiş olup tedavisi halen devam etmektedir. Bir olgu post-operoperatif 3. günde portal ven trombozu nedeniyle kaybedildi. Çıkarılan karaciğer histopatoloji raporları primer tanıları ile uyumlu bulundu.

Sonuç: Yeni kurulan bir organ nakli merkezinde erken dönemde ciddi bir komplikasyon görülmemesinin nedeni olarak, hasta seçimi, takip ve tedavilerinin dikkatli yapılmasına bağlı olduğunu düşünmekteyiz.

Anahtar kelimeler: Transplantasyon, Organ Nakli, Karaciğer Nakli

\section{Giriş}

İlk olarak Starzl tarafından yapılan karaciğer nakli son dönem karaciğer yetersizliğinde güncel tedavi olmakla birlikte, son yıllarda açılan yeni merkezlerin katkısı ile ülkemizde de bu konuda önemli gelişmeler olmaktadır (1).

\begin{abstract}
Objective: Liver transplantation is the current treatment for end-stage liver failure. In this study, we aimed to present our experience with cadaveric donor 7 liver transplants between 30.07.2015 and 30.07.2016 in our newly established organ transplant center.
\end{abstract}

Material-Method: The organs were provided from brain deaths declared cadavers in hospitals linked to the coordination system in Isparta and its district. Organ pairings were achieved according to the data of the Ministry of Health. All livers were transplanted orthotopic and completely. Vena cava anastomosis were performed the piggy-back method by applying partial clamping. Portal vein and hepatic artery anastomosis were performed end-to-end. Bile duct anastomosis were performed duct-to-duct over the stent.

Results: Seven patients ( 5 male, 2 female), mean age 55.3 (45-72) years, had cadaveric donor liver transplantation. Patients' characteristics, diagnosis, operation times, the amount of transfusion and complications are summarized. The histopathology reports of the removed livers were the compatible preoperative diagnosis. Acute myeloid leukemia (AML) was detected in one patient. No preoperative or early postoperative mortality were observed.

Conclusions: Since the establishment of our organ transplantation center 9 cadaveric donors were acquired to the national system and 6 liver transplantations were performed in our center. All of our patients were discharged without any complication. However, 6 months from the operation AML was diagnosed in one patient.

We consider that the reasons why no early complication are the patient selection, careful follow-up, and treatment of the patients in a newly established transplantation center.

Keywords: Transplantation, Organ Transplantation, Liver Transplantation
DOI: $10.22312 /$ sdusbed.297098

Müracaat tarihi: 09.03 .2017

Kabul tarihi: 24.03 .2017
Son yıllarda geliştirilen immün baskılama tedavileri ve cerrahi teknikler sayesinde karaciğer nakli, başta hepatit-B ve alkole bağlı siroz olmak üzere birçok karaciğer hastalığında uygulanmaktadır $(2,3)$.Özellikle geliştirilen organ saklama sıvıları da bu başarıda önemli bir faktördür (4). Endoskopik uygulamalardaki gelişmeler ile ameliyat sonrası dönemde

Yazışma Adresi / Corresponding: Cumhur Murat Tulay, Süleyman Demirel Üniversitesi Tıp Fakültesi, Genel Cerrahi AD, 32260, Çünür, Isparta, Türkiye. Tel: $05055615647 /+902462119248$

Fax: +902462112830

E-mail: drihsanyildiz@gmail.com 
görülen safra kaçakları, safra yolu darlıkları gibi geç komplikasyonlar endoskopik olarak tedavi edilebilmekte bu sayede mortalite ve morbidite oranları da azalt1labilmektedir (5). Cerrahi tekniklerdeki başarılı ve farklı uygulamalarla özellikle soğuk iskemi ve yoğun bakımda kalış süresi ile kanamanın azaltılmasında önemli katkılar sağlanmıştır (6). Bu gelişmelerle ülkemizde kurulan birçok organ nakli merkezinde çok sayıda karaciğer nakli yapılmaya devam edilmektedir (1).

$\mathrm{Bu}$ yazıda yeni kurulan Organ Nakli Merkezimizde 30.07.2015 ile 30.07.2016 tarihleri arasında yapılan 7 kadavra vericili karaciğer nakli sonuçlarımızı ve deneyimlerimizi sunmayı amaçladık.

\section{Materyal-Method}

Organlar Isparta ve bölgedeki koordinasyon sistemine bağlı hastanelerde ortaya çıkan beyin ölümü deklare edilmiş ve organ bağışı için aile rızası alınan kadavralardan sağlandı. Organ eşleşmeleri sağlık bakanlığına bağlı ulusal organ koordinasyon ve paylaşım sistemi verileri doğrultusunda gerçekleşti. Olguların demografik özellikleri, ameliyat süreleri, yapılan transfüzyon, komplikasyonlar ve Model of Score for End-Stage Liver (MELD) skorları geriye dönük olarak incelendi. Bütün ameliyatlar Süleyman Demirel Üniversitesi Organ Nakli Merkezinde aynı ekip tarafından gerçekleştirildi. Merkezimizde ve dişardan gelen karaciğerlerde organ koruyucu olarak Histidin-TriptofanKetoglutarat (HTK) solüsyonu kullanıldı. Laparotomi insizyonunda Makuuchi'nin tarif ettiği subkostal insizyon uyguland. Tümü tam ve ortotopik olarak nakledilen karaciğerlerin vena kava anastomozları No: 4/0 polipropilen sütur kullanılarak, devamlı dikiş tekniği, piggy-back yöntemi ve parsiyel klempaj uygulanarak yapıldı. Portal ven anastomozları ise standart olarak No: 6/0 polipropilen sütur kullanılarak devamlı dikiş tekniği ile uç-uca yapıldı. Vena kava ve portal ven anastomozlarını takiben önce portal ven klempi açılarak ileriye doğru teknikle karaciğer venöz perfüzyonu sağlandı. Hepatik arter anastomozu arter çapına göre No: 7/0-8/0 polipropilen sütur ile tek-tek yapıldı ve anastomozu takiben arteryel perfüzyon başlatıldı. Karaciğerin safra yapımı görüldükten sonra safra anastomozları stent üzerinden No: 4-6/0 polidiaksonon sütür ile arka duvar devamlı ön duvar ise tek-tek dikiş tekniği ile uç-uca yapıldı. Kanama kontrolünü takiben karaciğer altına ve anastomoz hattına dren konuldu. Post-operatif dönemde yoğun bakım ünitesine alınan olgular anestezi ve yoğun bakım uzmanları ile birlikte takip edildi.

\section{Sonuçlar}

Organ nakli merkezinin kurulduğu tarihten bu yana 9 adet kadavra donör ulusal sisteme kazandırılmış olup, 7 hastaya karaciğer nakli ise merkezimizde yapıldı. Yaş ortalaması (minimum-maksimum) 55,3 (45-72) olan toplam 7 olguya (5 erkek, 2 kadın) kadavra donörlü karaciğer nakli yapıldı. Hiçbir olguda kanama, kesi yeri enfeksiyonu ve ayrılması ile safra kaçağı gibi erken cerrahi komplikasyon olmadi. Olguların özellikleri, ameliyat süreleri, yapılan transfüzyon, komplikasyonlar ve MELD skorları Tablo 1'de özetlenmiştir. Reperfüzyona bağlı parankimal hasar veya kardiyak arrest olmad$_{1}$ ve primer non-fonksiyon görülmedi. Yoğun bakımda kalış süreleri ortalama (minimum-maksimum) 3,6 gün (2-6) idi.

Table 1. Hastaların demografik, preoperatif tanı, operasyon süre, transfüzyon ihtiyacı, komplikasyon ve Model of Score for End-Stage Liver (MELD) skor bilgileri

\begin{tabular}{cccccccc}
\hline Hasta no & Yaş & Cinsiyet & Preoperatif Tanı & $\begin{array}{c}\text { Operasyon } \\
\text { Süresi (dk) }\end{array}$ & $\begin{array}{c}\text { Tranfüzyon } \\
\text { (ünite) }\end{array}$ & Komplikasyon & MELD Skorları \\
\hline 1 & 72 & E & Primer biliyer siroz & 345 & 3 ES, 5 TDP & - & 22 \\
\hline 2 & 62 & E & Hepatit-B & 250 & 4 ES, 7 TDP & - & 27 \\
\hline 3 & 45 & K & Primer biliyer siroz & 330 & 12 ES, 12 TDP & Biliyer darlık & 32 \\
\hline 4 & 46 & E & Hepatit-B & 265 & 1 ES, 3 TDP & - & 24 \\
\hline 5 & 46 & E & Alkolik siroz & 240 & 3 ES, 5 TDP & - & 31 \\
\hline 6 & 61 & E & Alkolik siroz & 360 & 9 ES, 7 TDP & - & 21 \\
\hline 7 & 56 & K & Hepatit-B & 245 & 5 ES, 6 TDP & - & 21 \\
\hline
\end{tabular}

E: Erkek, K: Kadın, ES: Eritrosit süspansiyonu, TDP: Taze donmuş palzma

Bir kadın olguda 7. ayda biliyer darlık gelişti ve endoskopik olarak tedavi edildi. Yine aynı hastada ameliyat sonrası 8. ayda sırtın sol kısmında zona-zoster teşhisi konuldu ve medikal tedavi ile iyileşti. Bir hastamızda ise 6. ayda akut miyeloid lösemi tespit edilmiş olup tedavisi halen devam etmektedir. Bir olgu ameliyat sonrası 3. günde portal ven trombozu nedeniyle kaybedildi. Çıkarılan karaciğer histopatoloji raporları primer tanıları ile uyumlu bulundu.

\section{Tartışma}

Son dönem karaciğer yetersizliğinin güncel tedavisi kadavra donörlü veya canlı donörlü karaciğer naklidir ve ülkemizde bu tedavi yaklaşımı son zamanlarda giderek başarılı bir şekilde artmaktadır. Bilindiği gibi birçok ülkede kadavra donörlü karaciğer nakli yapılmakta ancak artan talep karşılanmadığ1 için canlı vericili karaciğerler daha çok kullanılmaktadır (1). Biz de yeni kurulan organ nakli merkezimizde çeşitli nedenlerle karaciğer yetersizliği olan 7 adet olguya kadavra donörlü karaciğer nakli yaptık. MELD skorları üzerine yapılan bazı çalışmalarda sağ kalıma etkiler araştırılmış ve $25^{\prime}$ in altında üç aylık sağ kalımın daha iyi olduğu görülmüştür (7, 8). Biz de yeni kurulan bir merkez olmamız nedeniyle hasta 
seçimine önem verdik. Hastalarımızda MELD skoru ortalama 25,4 (21-32) idi. MELD skoru 32 den yüksek olan hastaları daha deneyimli merkezlere yönlendirilmiştir.

Lopez ve arkadaşları 187-236 olguluk iki seride safra anastomozunda stent kullanmanın biliyer darlık ilişkisine bakmışlar ve ortalama \%17,3 oranında darlık tespit etmişlerdir. Ancak stent kullanıp kullanmama arasında bir fark görmemişlerdir. Bununla birlikte koledok çap1 $7 \mathrm{~mm}$ nin altındaki olgularda stent konulmasını önermektedirler $(5,9)$. Biz safra yolu anastomozlarında koledok çapına bakmadan rutin olarak stent kullanmayı tercih ettik. Buna rağmen bir hastamızda 7. ayda safra yolu darlığı gelişti (\%14) ve endoskopik girişimle tedavi edildi.

Fukazawa ve arkadaşları yaptıkları çalışmada reperfüzyona bağlı kardiyak arrest ve karaciğer parankim hasarında kaçınmak amacıyla karaciğer venöz perfüzyonunu vena kavadan geriye doğru yapmışlar ve bu uygulamanın kardiyak arrest riskini azalttığını bildirmişlerdir (3). Biz tüm olgularda karaciğer venöz perfüzyonunu portal venden ileriye doğru yaptık ve herhangi bir kardiyak komplikasyon yaşanmadı. Bunun nedeninin ise perfüzyonla birlikte karaciğeri ve karın içini 1lık serum fizyolojikle 1sıtıp ameliyat süresince hastanın vücut sıcaklığını da yakın takip ederek hastalarımızı mümkün olduğunca normo-termik seviyede tutmak olduğunu düşünmekteyiz. Safra yolu darlıklarında kullanılan solüsyonların etkileri konusunda tartışmalar devam etmekte ve bu konuda henüz bir fikir birliğine varılamamıştır (4). Biz merkezimizde koruma solüsyonu olarak Histidin-TriptofanKetoglutarat (HTK) solüsyonu kullanıldık ancak burada tercih nedenimiz bu solüsyonun daha hesaplı olmasıydı. Yaptığımız araştırmada birçok merkezin de bu solüsyonu aynı nedenlerle kullandığını gördük.

Karaciğer naklinde ameliyat sırasında ve ameliyat sonrası erken dönemde mortaliteye etki eden en ciddi neden olarak kanamalar görülmektedir. Ayrıca kan ve kan ürünü verilmesine ait komplikasyonlar da görülmekte sonuçta yoğun bakım ve hastanede kalış süreleri uzamaktadır (6). Biz bu nedenleri en aza indirmek için dikkatli bir diseksiyonla organı çıkarıp hassas kanama kontrolü ile hastalarımızın yoğun bakımda kalış sürelerini ortalama 3,6 günde tuttuk. Ortalama kan transfüzyonumuz ortalama (minimum-maksimum) 5,5 (3-12) ünite idi. Hiçbir hastamızda kanama veya başka nedenlerle tekrar laparotomi yapılmad1.

Sonuç olarak yeni kurulan bir organ nakli merkezinde erken dönemde ciddi bir komplikasyon görülmemesini uygun hasta seçimi, takip ve tedavilerinin dikkatli yapılmasına bağlı olduğunu düşünmekteyiz.

Çıkar Çatışması Beyanı: Yazalar arasında çıkar çatışması yoktur.

Açıklama: Bu makale; 2017 Joint International Congress of ILTS, ELITA \& LICAGE (24-27 May 2017 Prague, Czech Republic) Kongresinde No. P-534 Nolu Poster olarak ve 14. Ulusal Hepato-Gastroenteroloji Kongresi | 5. Ulusal Gastroenteroloji Cerrahisi Kongresi | 16. Avrasya Gastroenteroloji (5-8 Nisan 2017 Antalya) Kongresinde No: 0031 sözlü sunum olarak kabul edilmiştir.

\section{Teşekkür}

S.D.Ü. Organ Nakli Koordinatörü Mehmet Zeki Er'e emekleri için teşekkür ederiz.

\section{Kaynakça}

1. Akbulut S, Yilmaz S. Liver transplantation in Turkey: historical review and future perspectives. Transplant Rev (Orlando). 2015; 29(3): 161-7.

2. Petrowsky H, Busuttil RW. Evolving surgical approaches in liver transplantation. Semin Liver Dis. 2009; 29(1): 121-33.

3. Fukazawa K, Nishida S, Hibi T, Pretto EA Jr. Crystalloid flush with backward unclamping may decrease postreperfusion cardiac arrest and improve short-term graft function when compared to portal blood flush with forward unclamping during liver transplantation. Clin Transplant. 2013; 27(4): 492-502.

4. Kaltenborn A, Gwiasda J, Amelung V, Krauth C, Lehner F, Braun F. Comparable outcome of liver transplantation with histidine-tryptophan-ketoglutarate vs. University of Wisconsin preservation solution: a retrospective observational double-center trial. BMC Gastroenterol. 2014; 14: 169.

5. Mejía GA, Olarte-Parra C, Pedraza A, Rivera JB, Benavides CA. Biliary Complications After Liver Transplantation: Incidence, Risk Factors and Impact on Patient and Graft Survival. Transplant Proc. 2016; 48(2): 665-8.

6. Schrem H, Klußmann A, Focken M, Emmanouilidis N, Oldhafer F, Klempnauer J. Post-Operative Hemorrhage After Liver Transplantation: Risk Factors and Long-Term Outcome. Ann Transplant. 2016; 21: 46-55.

7. Aranzana EM, Coppini AZ, Ribeiro MA, Massarollo PC, Szutan LA, Ferreira FG. Model for End-Stage Liver Disease, Model for Liver Transplantation Survival and Donor Risk Index as predictive models of survival after liver transplantation in 1,006 patients. Clinics (Sao Paulo). 2015; 70(6): 413-8.

8. Morell B, Dufour JF. Liver transplantation - when and for whom it should be performed. Ther Umsch. 2011; 68(12): 707-13

9. López-Andújar R, Orón EM, Carregnato AF, Suárez FV, Herraiz AM, Rodríguez FS. T-tube or no T-tube in cadaveric orthotopic liver transplantation: the eternal dilemma: results of a prospective and randomized clinical trial. Ann Surg. 2013; 258(1): 21-9. 